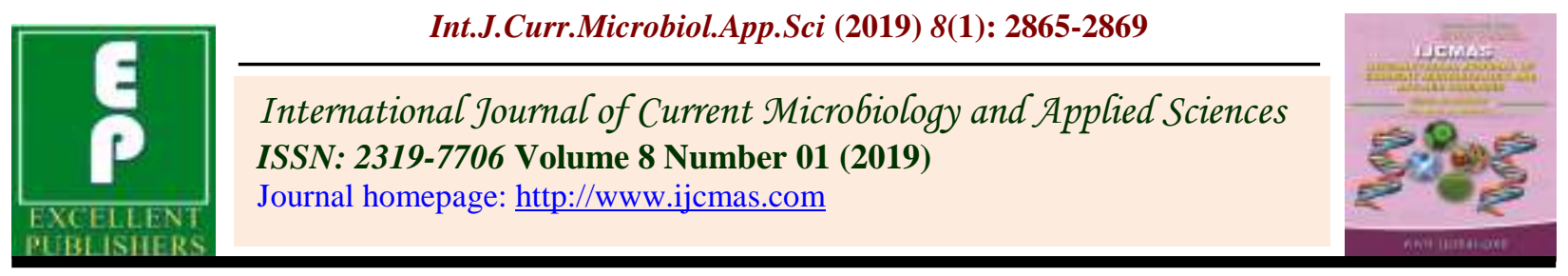

Original Research Article

https://doi.org/10.20546/ijcmas.2019.801.301

\title{
Establishment of Seed Borne Nature of Alternaria alternata causing Alternaria Leaf Spot and Fruit Rot of Chilli
}

\author{
Manjul Pandey*, R.P. Mishra and Mukesh Srivastava
}

Department of Plant Pathology, C. S. Azad University of Agriculture \& Technology, Kanpur-208002(India)

*Corresponding author

\section{A B S T R A C T}

Keywords

Chilli (Capsicum annuиm), Seed borne, Alternaria alternata, Leaf spot, Fruit rot

Article Info

Accepted: 17 December 2018 Available Online: 10 January 2019
Study on seed-borne nature of Alternaria alternata in chilli seeds indicated that in Standard blotter method, the incidence of A. alternata was 5.7 to $15.3 \%$ (average, 9.5\%) and 16.5 to $28.4 \%$ (average, 21.7\%) with unsterilzied seeds collected from general fields and diseased fields, respectively. The incidence for surface sterilized seeds from general and diseased fields were 2.6 to $7.2 \%$ (average, $4.9 \%$ ) and 7.8 to $13.0 \%$ (average, 9.6\%), respectively. In Agar plate method with Potato dextrose agar medium, the incidence of Alternaria alternata was 4.0 to $10.5 \%$ (average, $7.4 \%$ ) and 11.0 to $24.0 \%$ (average, $18 \%$ ) with surface sterilized.

\section{Introduction}

Chilli (Capsicum annuum L.) is an indispensable condiment as well as vegetable in every household in India. No Indian dish, either vegetarian or non-vegetarian is complete without it.

Chillies are valued throughout the world for its pungency, aroma and medicinal value. Chillies are the major and the cheapest source of Vitamin C, A and P. Chilli fruits are used as an irritant for rheumatism or neuritis. Chilli is a unique crop among spices being the only source of capsaicin $\left(\mathrm{C}_{18} \mathrm{H}_{27} \mathrm{NO}_{3}\right)$-an alkaloid, which is a mixture of seven closely related alkyl vanillyamides named capsaicinoides. The red colour of the fruit is due to the pigment capsanthin (Nath, 1969).

In the present investigation, the leaf spot and fruit rot incited by Alternaria alternata (Fr.) Keissler has been identified a major constraint in the production of chillies. The fungus is responsible for seed rot, seedling decay, leaf spot, fruit rot and tender tip drying at different stages of crop growth (Courter et al., 1965; Suryanarayana, 1978). 


\section{Materials and Methods}

Seed samples of chilli variety Chaman were collected from diseased plants of different localities of Kanpur for detection of the pathogen. These samples were stored in poly bags at room temperature at $20^{\circ}-30^{\circ} \mathrm{C}$ and relative humidity 40-60 percent for further studies. Seed borne nature of Alternaria alternata was studied by two methods viz., Standard blotter method and Agar plate method (ISTA, 1985).

\section{Standard blotter method}

Three circular pieces of blotter papers of the size of Petridish were cut and dipped in sterilized water. The excess water was drained off and placed in each sterilized Petridish. Twenty-five chilli seeds were placed in each Petridish with the help of sterile forcep under sterile conditions in the incubation chamber (16 seeds in outer circle, eight in the inner and one in the centre) so as to allow equal distance between seeds. The plated Petridishes were kept for incubation in the growth chamber. Two hundred pretreated and untreated seeds of each sample were tested. Seeds were pretreated with 0.1 percent mercuric chloride for 30 seconds and then washed in three changes of sterile water. Petridishes were examined on the eighth day of incubation. Fungi were observed and identified by on the basis of colony and habit characters under stereoscopies binocular.

\section{Agar plate method}

Potato dextrose agar medium was used in this method. In each sterilized Petri dish, ten pretreated seeds were placed with the help of sterilized forceps on $20 \mathrm{ml}$ solidified PDA medium at equal distance, nine in outer ring and one in the centre. Observations on the associated fungi were recorded on the fifth day of incubation with the help of making slides of growing fungi.

\section{Results and Discussion}

\section{Standard blotter method}

\section{In surface un-sterilized seed}

Presence of Alternaria alternata infection in seeds was assumed using Standard blotter method after screening from seed samples of susceptible variety 'Chaman'. Twenty seed samples, ten each from general and diseased field were collected. The seeds were not pretreated and were plated as such.

Observation summarized in Table 1 showed that 5.7 to 15.3 per cent infection with an average infection of 9.5 per cent in seeds collected from general fields, while the corresponding figures in seeds collected from diseased fields ranged from 16.5 to 28.4 per cent with an average of 21.7 per cent.

\section{In surface sterilized seeds}

The extent of Alternaria alternata infection in the internal tissues of the surface sterilized seeds was assumed through Standard blotter method. Twenty seeds samples, ten each from general and diseased fields were compared for the presence of Alternaria alternata in the seeds.

Observations on four hundred seeds from each seed sample (Table 2) revealed 2.6 to 7.2 per cent internal seed infection by Alternaria alternata in different seeds samples collected from general fields with an average of 4.9 per cent. Similarly, the infection of Alternaria alternata in seed samples of diseased fields ranged from 7.8 to 13.0 per cent with an average of 9.6 per cent.

\section{Agar plate method}

Ten samples of the susceptible variety 'Chaman' was assessed for Alternaria 
alternata infection by employing Agar plate method with Potato dextrose agar medium. Two hundred surface disinfected seeds in $1 \%$ chlorine sample were tested. The disinfection of the seeds was done for removing the surface weak contaminants, as these overgrew over Alternaria alternata in plates. The data presented in Table 3 revealed that 4.0 to 10.5 per cent colonies (mean 7.4 per cent) grew over and around the seeds in different seed samples, collected from general fields of variety 'Chaman' in agar plate method with Potato agar medium. The incidence of seed borne infection of Alternaria alternata varied 11.0 to $24.0 \%$ with mean incidence of 18 per cent in the samples of chillies of variety Chaman.

Table.1 Per cent infection of Alternaria alternata in surface unsterilized seeds of chilli variety 'Chaman' collected from general and diseased fields using Standard blotter method

\begin{tabular}{|c|c|c|}
\hline \multirow{2}{*}{$\begin{array}{c}\text { Sample } \\
\text { No. }\end{array}$} & \multicolumn{2}{|c|}{ Per cent infection in } \\
\hline 1. & & Diseased fields \\
\hline 2. & 7.2 & 18.4 \\
\hline 3. & 8.4 & 20.2 \\
\hline 4. & 5.7 & 19.2 \\
\hline 5. & 9.3 & 16.5 \\
\hline 6. & 12.5 & 20.1 \\
\hline 7. & 13.1 & 24.0 \\
\hline 8. & 8.5 & 26.4 \\
\hline 9. & 9.1 & 21.9 \\
\hline 10. & 15.3 & 22.6 \\
\hline Average & $\mathbf{9 . 5}$ & 28.4 \\
\hline
\end{tabular}

Table.2 Per cent infection of Alternaria alternata in surface sterilized seeds of chilli variety 'Chaman' collected from general and diseased fields using Standard blotter method

\begin{tabular}{|c|c|c|}
\hline \multirow{2}{*}{ Sample No. } & \multicolumn{2}{|c|}{ Per cent infection in } \\
\cline { 2 - 3 } & General fields & Diseased fields \\
\hline 1. & 3.9 & 8.1 \\
\hline 2. & 4.2 & 8.2 \\
\hline 3. & 2.6 & 7.8 \\
\hline 4. & 5.3 & 9.2 \\
\hline 5. & 4.1 & 10.1 \\
\hline 6. & 6.3 & 7.9 \\
\hline 7. & 5.8 & 8.1 \\
\hline 8. & 6.0 & 11.4 \\
\hline 9. & 7.2 & 12.3 \\
\hline 10. & 4.3 & 13.0 \\
\hline Average & $\mathbf{4 . 9}$ & $\mathbf{9 . 6}$ \\
\hline
\end{tabular}


Table.3 Per cent infection of Alternaria alternata in seeds of chilli variety 'Chaman' collected from general and diseased fields using Agar plate method with Potato dextrose agar medium

\begin{tabular}{|l|c|c|}
\hline \multirow{2}{*}{$\begin{array}{c}\text { Sample } \\
\text { No. }\end{array}$} & \multicolumn{2}{|c|}{ Per cent infection in } \\
\hline 1. & General fields & Diseased fields \\
\hline 2. & 6.0 & 12.0 \\
\hline 3. & 5.0 & 11.0 \\
\hline 4. & 8.5 & 16.0 \\
\hline 5. & 8.0 & 15.0 \\
\hline 6. & 10.5 & 24.0 \\
\hline 7. & 4.0 & 20.0 \\
\hline 8. & 6.0 & 22.0 \\
\hline 9. & 10.0 & 23.0 \\
\hline 10. & 7.0 & 18.0 \\
\hline Average & 9.0 & 19.0 \\
\hline
\end{tabular}

The incidence of Alternaria alternata ranged of from 5.7 to 15.3 with an average of 9.5 per cent on the seeds, collected from general fields in Standard blotter method whereas corresponding figures of seed infection of Alternaria alternata was 16.5 to 28.4 per cent (mean percentage, 21.7) in the seed collected from diseased fields. However, the surface sterilized seeds from general and diseased fields showed infection in the range of 2.6 to 7.2 per cent (average, $4.9 \%$ ) and 7.8 to 13.0 per cent (mean percentage, 9.6), respectively.

Similar studies with Potato dextrose agar medium on Agar plate method with same set of seed samples gave identical. The seeds sterilized with $1 \%$ mercuric chloride, in general were found to yield much lower colonies of Alternaria alternata in agar plates. The incidence of Alternaria alternata infection ranged from 4.0 to 10.5 per cent (average, $7.4 \%$ ) in seeds collected from general fields. The corresponding figures in seeds collected from diseased fields were 11.0 to 24.0 per cent (average, 18\%). These findings are in agreement with the observations of Rout and Rath (1972) also found seed borne nature of chilli and these fungi have associated with seeds at the time of extraction or during storage time. They also affect seed germination and seedling vigour. Bhale et al., (1999) also found standard blotter method superior in the detection of Alternaria alternata with chilli seeds.

\section{References}

Bhale, U.; Bhale, M.S. and Khare, M.N. (1999). Efficacy of methods in detection of Alternaria alternata on chilli seeds. Indian. J. Mycol. Pl., Pathol., 29: 125126.

Courter, J.W.; Shurtleff, M.C.; Quebral, P.C. and Thompson, A.E. (1965). Field susceptibility of pepper varieties and selections to fruit rot caused by Alternaria tenuis. Pl. Dis. Reptr., 49 (11): 866-870.

ISTA (1985). International Rules for Seed Testing Annexes. Seed. Sci. Technol., 13: 307-355.

Nath, P. (1969). Vegetables for the Tropical Region. Indian Council of Agricultural Research, New Delhi, Book Series No.(2).p.12 
Rout, B.K. and Rath, G.C. (1972). Note on seed borne diseases of chilli (Capsicum annuum L.). Indian Phytopath., 25(4): 597-598.
Suryanarayana, D. (1978). Seed Pathology. Vikas Pub. House Pvt. Ltd., New Delhi, p. 111.

\section{How to cite this article:}

Manjul Pandey, R.P. Mishra and Mukesh Srivastava. 2019. Establishment of Seed Borne Nature of Alternaria alternata causing Alternaria Leaf Spot and Fruit Rot of Chilli. Int.J.Curr.Microbiol.App.Sci. 8(01): 2865-2869. doi: https://doi.org/10.20546/ijcmas.2019.801.301 